\title{
Rancang Bangun Alat Praktikum Untuk Menentukan Superposisi Gelombang Bunyi
}

\author{
M. Tahir \\ Pendidikan Fisika Universitas Ahmad Dahlan \\ J1. Prof. Dr. Soepomo SH. Warungboto UH IV Yogyakarta \\ Surat-e: muhammadtahirbelitung@gmail.com
}

Penelitian menentukan superposisi bunyi telahh dilakukan dengan meenggunakan dua speaker sebagai sumber suara, dua audio frekuensi generator (AFG), amplifier sebagai penguat, tabung, dan sensor suara serta software logger pro. Bunyi yang dihasilkan oleh masing-masing sumber suara direkam dengan menggunkan sensor suara dan ditampilkan dalam bentuk gelombang dalam tampilan logger pro. Tiap sumber suara menghasilkan gelombang bunyi sendiri. Superposisi gelombang bunyi terjadi bila kedua sumber suara dihidupkan bersama. Jarak antar kedua sumber suara mempengaruhi bentuk superposisi gelombang bunyi. Data yang diperoleh pada tampilan logger pro kemudian dilakukan analisis grafik menggunakan Microsoft Excel, dari hasil analisis dapat diketahui superposisi gelombang bunyi secara konstruktif dan secara distruktif.

Hasil penelitian menunjukan bahwa rancang bangun alat praktikum untuk menentukan superposisi gelombang bunyi dapat bekerja dengan baik. Terbukti dapat menunjukan superposisi gelombang bunyi desktruktif dan superposisi gelombang bunyi konstruktif.

Kata kunci: Gelombang bunyi, superposisi gelombang, logger pro

\section{Pendahuluan}

Superposisi merupakan kombinasi linear dari dari gelombang elektromagnetik. Prinsip superposisi berlaku untuk tegangan dan arus pada jalur transmisi, untuk listrik dan medan magnet di ruang bebas, dan energi baik dalam konteks ini [I]. Superposisi gelombang merupakan konsep dasar dalam gelombang dan optic. Hal ini memungkinkan studi dan penjelasan gangguan polaterns di optik [2].

Penggabungan pergeseran-pergeseran dari pulsa-pulsa yang terpisah disetiap titik untuk mendapat pergeseran yang sesungguhnya adalah contoh dari prinsip superposisi, bila dua gelombang bertumpang-tindik, maka pergeseran sesungguhnya dari sebarang titik pada dawai itu pada sebarang waktu didapatkan dengan menambahkan pergeseran yang akan dipunyai oleh titik itu seandainya hanya gelombang pertama yang hadir dan pergeseran yang akan dipunyai oleh titik itu seandainya hanya gelombang kedua yang hadir [3].

Prinsip superposisi secara fisis penting karena dapat mempermudah menganalisis gerak gelombang yang rumit menjadi satu gelombang sederhana [4].
Berdasarkan penelitian yang dilakukan [5] superposisi gelombang dapat terbentuk dari gabungan gelombanggelombang bunyi pukulan bonang burung yang direkam dengan software audacity dan pemodelan superposisi gelombang dengan memanfaatkan program MATLAB. Penelitian ini bertujuan untuk menentukan gelombang superposisi dari kedua sumber suara.

\section{Kajian Pustaka}

\section{Prinsip superposisi}

Jika dua gelombang atau lebih merambat melalui sebuah medium, nilai yang dihasilkan dari fungsi gelombang di setiap titik adalah penjumlahan aljabar dari nilai-nilai fungsi dari masing-masing gelombang [6]. Fungsi gelombang yang melukiskan gerak yang dihasilkam dalam situasi ini didapatkan dengan menambahkan kedua fungsi gelombang untuk kedua gelombang yang terpisah tersebut [3].

Secara matematis, sifat tambahan dari fungsi-fungsi gelombang diperoleh dari bentuk persamaan gelombang:

$$
\frac{\partial^{2} y(x, t)}{\partial x^{2}}=\frac{1}{v^{2}} \frac{\partial^{2} y(x, t)}{\partial t^{2}}
$$

atau 


$$
\frac{\partial^{2} y}{\partial x^{2}}=\frac{\mu}{F} \frac{\partial^{2} y}{\partial t^{2}}
$$

Persamaan itu mengandung fungsi $y(x, t)$ hanya sampai pangkat pertama. Sebagai akibatnya, jika sebarang dua fungsi $y_{1}(x, t)$ dan $y_{2}(x, t)$ memenuhi persamaan gelombang itu secara terpisah, maka jumlah $y_{1}(x, t)+y_{2}(x, t)$ juga memenuhi persamaan gelombang $[4]$.

\section{Interferensi gelombang}

Interferensi menunjukan efek-efek fisis yang timbul karena superposisi dua atau lebih deret gelombang. Tinjau dua gelombang yang frekuensinya sama dan amplitudonya sama yang merambat dengan laju yang sama didalam arah $(+\mathrm{x})$ yang sama tetapi dengan perbedaan fase $\phi$ diantara kedua gelombang tersebut. Persamaan-persamaan kedua gelombang tersebut adalah:

$$
y_{1}=y_{m} \sin (k x-\omega t-\phi)
$$

dan

$$
y_{2}=y_{m} \sin (k x-\omega t)
$$

Dapat dituliskan kembali persamaan pertama didalam dua bentuk yang ekivalen:

$$
y_{1}=y_{m} \sin \left[k\left(x-\frac{\phi}{k}\right)-\omega t\right]
$$

atau

$$
y_{1}=y_{m} \sin \left[k x-\omega\left(t+\frac{\phi}{k}\right)\right]
$$

Gelombang resultan dari superposisi adalah jumlah dari persamaan (3) dan (4), yaitu:

$$
y=y_{1}+y_{2}=y_{m}[\sin (k x-\omega t-\phi)+(k x-\omega t)]
$$

Dari persamaan geometris untuk jumlah sinus dari dua sudut

$$
\sin B+\sin C=2 \sin \frac{1}{2}(B+C) \cos \frac{1}{2}(C-B)
$$

Didapatkan $[8]$

$$
\begin{aligned}
y & =y_{m}\left[2 \sin \left(k x-\omega t-\frac{\phi}{2}\right) \cos \frac{\phi}{2}\right] \\
& =\left(2 y_{m} \cos \frac{\phi}{2}\right) \sin \left(k x-\omega t-\frac{\phi}{2}\right)
\end{aligned}
$$

Superposisi dua gelombang yang frekuensi dan amplitudo sama yang hampir sefase menghasilkan sebuah gelombang yang amplitudonya hampir dua kali amplitudo masing-masing gelombang, maka gelombang-gelombang tersebut dikatakan berinteferensi secara konstruktif [3].

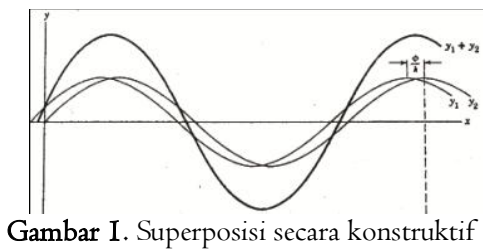

Superposisi dua gelombang yang frekuensi dan amplitudony sama dan berbeda fase hampir $180^{\circ}$ menghasilkan sebuah gelombang yang amplitudonya hampir sama dengan nol, maka gelombang-gelombang tersebut dikatakan berinterferensi secara desktruktif [4].

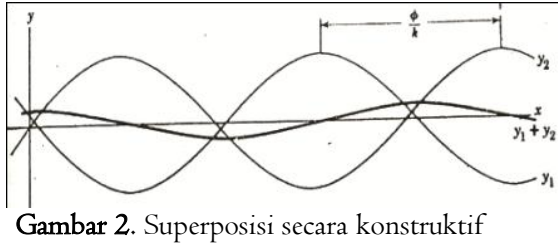

\section{Kurva lissajous}

Kurva lissajous yaitu sebuah penampakan pada layar osiloskop yang menunjukkan perbedaan atau perbandingan beda fase, frekuensi dan amplitudo dari kedua input [7].

Sudut fase pada kurva lissajous dapat ditentukan dengan menggunakan persamaan [8]:

$$
\phi=\sin ^{-1}\left(\frac{D}{C}\right)
$$

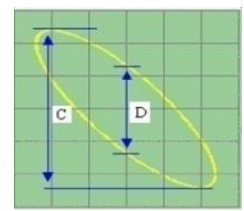

Gambar 3. Kurva lissajous

\section{Metode Penelitian/Eksperimen}

\section{Alat penelitian}

AFG, amplifier, interface, sensor suara (microphone), tabung, speaker, laptop dan software logger pro.

\section{Desain penelitian}

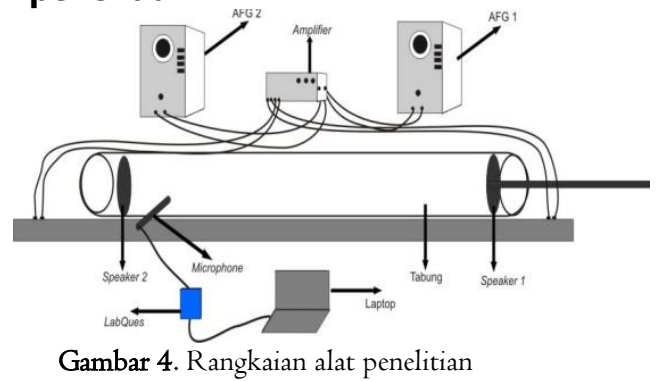

Prosedur percobaan meliputi, menyiapkan alat dan bahan yang akan digunakan dalam penelitian, menyusun alat 
dan bahan penelitian seperti pada gambar 3, mengatur skala frekuensi pada AFG I dan AFG 2, Mengatur volume pada amplifier, membuka software loger pro pada laptop, engatur jarak antara kedua sumber bunyi, menghidupkan AFG I dan AFG 2 dalam keadaan off, mengamati grafik yang hasilkan dari sumber suara I pada tampilan logger pro, menghidupkan AFG 2 dan AFG I dalam keadaan off, mengamati grafik yang dihasilkan dari sumber suara 2 pada tampilan logger pro, menghidupkan AFG I dan AFG 2, engamati grafik yang dihasilkan dari sumber suara I dan sumber suara 2 pada tampilan logger pro, dan mengulangi langka g sampai 1 untuk jarak dan frekuensi yang berbeda.

\section{Analisi data}

Metode analisis data yang digunakan dalam penelitian ini adalah dengan menggunakan analisis Logger Pro dan Microsoft Excel, yaitu dengan membuat grafik ketika masing-masing sumber suara di hidupkan dan ketika kedua sumber dihidupkan secara bersama-sama yang nanti akan terlihat grafik superposisi gelombang yang dihasilkan.

\section{Hasil Penelitian dan Pembahasan}

\section{Frekuensi 500 hz, jarak antar sumber 30,5} cm.

Diperoleh data tampilan pada logger pro sebagai berikut:
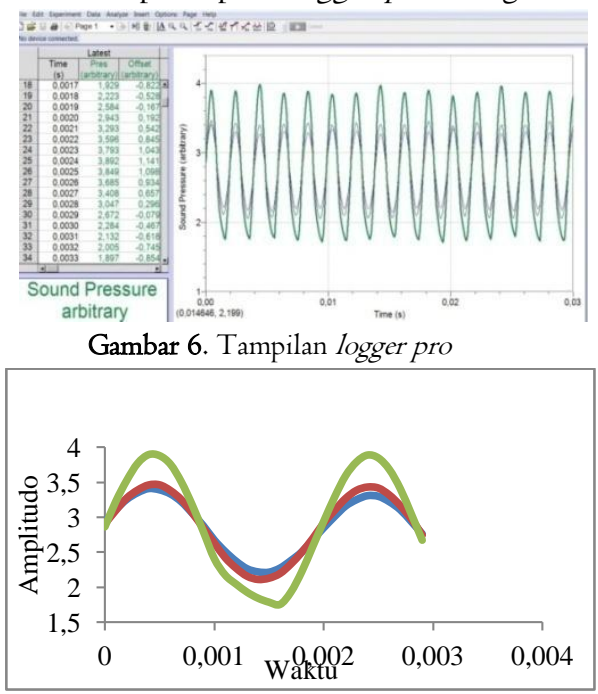

Gambar 7. Gabungan Gelombang

Dari grafik gabungan gelombang diatas, amplitudo untuk tiap-tiap gelombang dapat ditentukan, gelombang bunyi yang dihasilkam oleh sumber suara I memiliki amplitudo $(A)$ sebesar $0,59 \mathrm{~dB}$, gelombang bunyi yang dihasilkan oleh sumber suara 2 memiliki amplitudo $(A)$ sebesar 0,67 $\mathrm{dB}$ dan amplitudo $(A)$ superposisi gelombang adalah resultan dari amplitudo kedua gelombang, yaitu $(A)$ sebesar I,26 dB. Dari gambar dapat terlihat bahwa amplitudo gelombang superposisi hampir dua kali amplitudo masing-masing gelombang. Dari teori yang sudah dipaparkan sebelumnya, maka gelombang-gelombang tersebut dikatakan berinterferensi secara konstruktif.

Dengan mensubtitusikan nilai-nilai fungsi kepersamaan (7), maka diperoleh persamaan gelombang total:

$$
y_{\text {total }}=1,26\left[2 \sin \frac{1}{2}(5,78 \pi x-2000 \pi t)\right]
$$

Dari data sumber suara I dan sumber suara 2 dapat diplot kedalam gelombang lissajous, sumber suara I sebagai $y_{1}$ dan sumber suara 2 sebagai $y_{2}$.

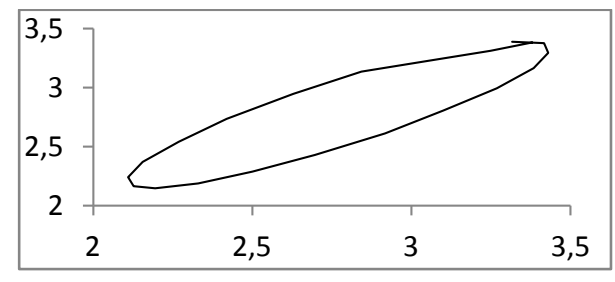

Gambar 8. Kurva lissajous

Sudut fase $(\phi)$ pada kurva lissajous tersebut dapat ditentukan dengan menggunakan persamaan (I0) dan diperoleh $\phi$ sebesar $27,2^{\circ}$.

\section{Frekuensi 300 Hz, jarak antar sumber 27,5 cm.}

Diperolah data tampilan pada logger pro sebagai berikit:

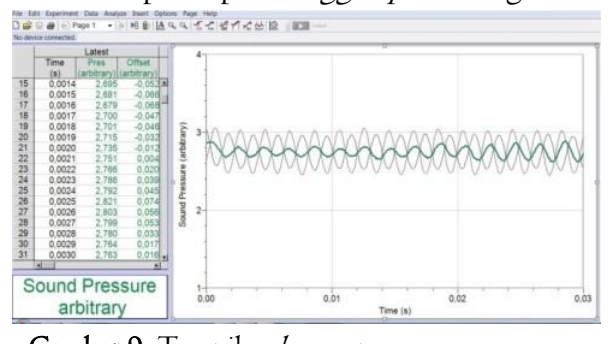

Gambar 9. Tampilan logger pro

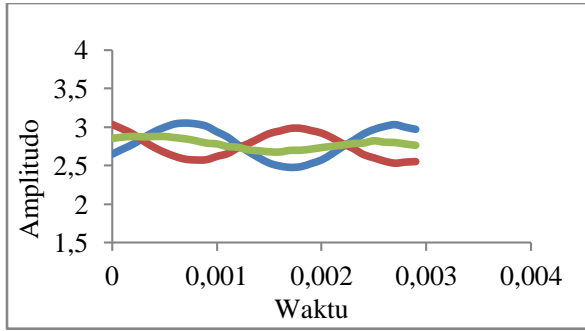

Gambar I0. Gabungan gelombang 
Dari grafik gabungan gelombang bunyi yang dihasilkan oleh sumber suara I, gelombang bunyi yang dihasilkan oleh sumber suara 2 dan superposisi gelombang bunyi, maka dapat terlihat gelombang bunyi sumber suara I dan gelombang bunyi sumber suara 2 berbeda fase $(\phi)$ hampir sebesar $180^{\circ}$. Gelombang bunyi yang dihasilkam oleh sumber suara I memiliki amplitudo $(A)$ sebesar $0,28 \mathrm{~dB}$, gelombang bunyi yang dihasilkan oleh sumber suara 2 memiliki amplitudo $(A)$ sebesar $0,2 \mathrm{IdB}$.

Amplitudo superposisi gelombang hampir sama dengan nol karena disebabkan terjadi beda fase $(\phi)$ hampir $180^{\circ}$. Dari teori yang sudah dipaparkan sebelumnya, maka gelombang-gelombang tersebut berinterferensi secara desktruktif. Dengan mensubtitusikan nilai-nilai fungsi kepersamaan (7), maka diperoleh persamaan gelombang total:

$$
y_{\text {total }}=0,7\left[2 \pi \sin \frac{1}{2}(3,44 x-2000 t-1) \cos \frac{1}{2}\right]
$$

Dari data sumber suara I dan sumber suara 2 dapat diplot kedalam gelombang lissajous, sumber suara I sebagai $y_{1}$ dan sumber suara 2 sebagai $y_{2}$.

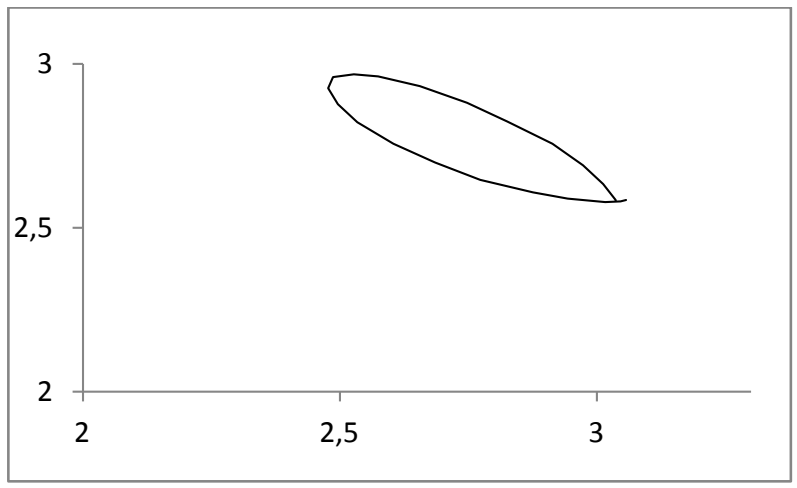

Gambar II. Kurva lissajous

Sudut fase $(\phi)$ pada kurva lissajous tersebut dapat ditentukan dengan menggunakan persamaan (10) dan diperoleh $\phi$ sebesar $30^{\circ}$.

\section{Kesimpulan}

Berdasarkan hasil penelitian dan analisis data yang telah dilakukan maka dapat diambil kesimpulan bahwa:

I. alat yang digunakan untuk praktikum, terbukti alat dapat menentukan superposisi gelombang bunyi yang memiliki kesesuaian dengan superposisi gelombang secara teori.
2. Superposisi gelombang bunyi konstruktif terjadi pada frekuensi $500 \mathrm{~Hz}$ dan jarak antar kedua sumber suara $30,5 \mathrm{~cm}$. Sedangkan untuk superposisi gelombang destruktif terjadi pada frekuensi $300 \mathrm{~Hz}$ dan jarak antar kedua sumber $27,5 \mathrm{~cm}$.

\section{Ucapan Terimakasih}

Terimah kasih kepada Dr. Moh. Toifur, M.Si yang telah membimbing dalam penelitian. Terimah kasih kepada Okimustava, M.Pd. Si, Edi Susanto, Eko Nursulistiyo, M.Si, Drs. Ishafit, M.Si dan kepada semua pihak yang banyak membantu dalam menyelesaikan penelitian ini.

\section{Kepustakaan}

[I] Schantz, H.G. On the Superposition and Elastic Recoil of Electromagnetic Waves. Forum for Electromagnetic Research Methods and Application Technologies (FERMAT).

[2] L. M. Arevalo Aguilar, C. Robledo-Sanchez, M. L. Arroyo Carrasco and M. M. Mendez Otero. The principle of superposition for waves: The amplitude and phase modulation phenomena. Natural Sciences Publishing Cor. Appl. Math. Inf. Sci. 6 No. 2, 307-315 (2012)

[3] Young, H. D. and Freedman, R. A, Fisika Universitas Edisi Kesepuluh Jilid 2, Jakarta: Erlangga, 2004.

[4] Halliday, David and Robert Resnick, Fisika Edisi Ketiga Jilid I, Jakarta: Erlangga, I985

[5] Widayanti, Lusi, Pengembangan Eksperimen Superposisi Gelombang Bunyi Bonang Barung Secara Simultan dan Mixing Berbantuan Audacity, Tesis, Program Study Magister Pendidikan Fisika, Yogyakarta, 2015.

[6] Serway, Raymond A and John W. Jewett, Fisika Untuk Sains dan Teknik, Jakarta: Salembah Teknik, 2004.

[7] Ramadhan, Pengertian Lissajous, Diagram Lissajous dan Cara Membaca, 20I4. Website: http://ambangramadhan.blogspot.com/2014/08/pengertian-lissajous-diagramlissajous.html, diakses tanggal I9 Agustus 2015.

[8] Chattopadhyay, D, Dasar Elektronika, Jakarta: UI-Pres, 1989 